To cite this manuscript, use the following citation

Atoui S, Chevance G, Romain AJ, Kingsbury C, Lachance JP, Bernard P. Daily associations between sleep and physical activity: A systematic review and meta-analysis.

Sleep Medicine Reviews https://doi.org/10.1016/j.smrv.2021.101426 
PREPRINT

\title{
Daily associations between sleep and physical activity: A systematic review and
}

\section{meta-analysis}

\author{
S. Atoui ${ }^{1,2}$, Chevance $\mathrm{G}^{3}$, A.J. Romain ${ }^{2,4}$, C. Kingsbury ${ }^{1,2}$, J.P. Lachance ${ }^{2}$, P. Bernard ${ }^{1,2^{*}}$
}

${ }^{1}$ Department of Physical Activity Sciences, Université du Québec à Montréal, Montréal, Québec, Canada

${ }^{2}$ Research Center, University Institute of Mental Health at Montreal, Montréal, Quebec, Canada

${ }^{3}$ Center for Wireless \& Population Health Systems, Department of Family Medicine and Public Health, UC San Diego, San Diego, CA 92093 USA

${ }^{4}$ École de kinésiologie et des sciences de l'activité physique, Faculté de Médecine, Université de Montréal, Montréal, Québec, Canada

*Correspondence concerning this article should be addressed to:

Paquito Bernard, PhD, Université du Québec à Montréal, Montréal, Canada

Faculté des sciences, UQÀM, Complexe des Sciences, Pavillon des sciences biologiques (SB),

Local: SB-4445, 141, Avenue du Président Kennedy, Montréal, Québec, Canada, H2X 1 Y4

bernard.paquito@uqam.ca

ORCID: https://orcid.org/0000-0003-2180-9135

@PaquitoBernard 


\section{Summary}

The day-to-day variations of sleep and physical activity are associated with various health outcomes in adults, and previous studies suggested a bidirectional association between these behaviors. The daily associations between sleep and physical activity have been examined in observational or interventional contexts. The primary goal of the current systematic review and meta-analysis was to summarize existing evidence about daily associations between sleep and physical activity outcomes at inter- and intraindividual level in adults. A systematic search of records in eight databases from inception to July 2019 identified 33 peer-reviewed empirical publications that examined daily sleep - physical activity association in adults. The qualitative and quantitative analyses of included studies did not support a bidirectional daily association between sleep outcomes and physical activity. Multilevel meta-analyses showed that three sleep parameters were associated with physical activity the following day: sleep quality, sleep efficiency, and wake after sleep onset. However, the associations were small, and varied in terms of direction and level of variability (e.g. inter- or intra-individual). Daytime physical activity was associated with lower total sleep time the following night at an inter-person level with a small effect size. Future studies should examine sleep and physical activity during a longer period and perform additional sophisticated statistical analyses.

Systematic review registration: https://osf.io/w6uy5/

Keywords: Ecological momentary assessment; sleep; insomnia; physical activity; exercise 


\section{Introduction}

Sleep and physical activity are both important health behaviors in the general population. It has been well-established that low physical activity levels and poor sleep are related to a wide range of medical problems and chronic health conditions, including cardiovascular disease, overweight and obesity, type 2 diabetes, depression, and anxiety disorders $(1,2)$. Furthermore, these behaviors are likely to interact with each other. Chennaoui et al. (3) presented potential biological pathways explaining possible reciprocal interactions between sleep and physical activity in the short- and long-term. They suggested that acute or repeated physical activity increased Total Sleep Time (TST) through a decrease of insulin resistance and inflammation markers concentration, better regulation of circadian rhythm, and release of brain-derived neurotrophic factor. In return, sleep deprivation could alter the physical performance or facilitate fatigue during physical activity by increasing cortisol concentration, decreasing growth hormone, and prolactin concentration and stimulating inflammation markers.

Long-term bidirectional associations between sleep and physical activity have been hypothesized in narrative reviews (3-5) and examined in prospective studies. Reciprocal relationships between better sleep quality and high physical activity were found over 3 years in samples of students (6) and adults aged 42 to 72 years (7) in longitudinal studies. Another 2-year longitudinal study found a unidirectional, positive, and significant association between sleep quality and physical activity among community-dwelling older adults (8).

Short-term associations between sleep and physical activity have also been experimentally tested. Previous investigations examined the temporal consequences of a sleep-deprived night on physical activity. An induced sleep restriction was associated with a significantly lower time spent in objectively measured physical activity the following day, as well as the lower intensity of activity $(9,10)$. However, a contradictory finding was found in another investigation showing that increased energy expenditure was observed the day following a short night (11). The other side of this association whether physical activity is associated with sleep the following night; have been tested in a recent meta-analysis of experimental studies. This meta-analysis concluded that a session of physical exercise was associated with higher Sleep Efficiency (SE), TST, lower Sleep of Latency (SOL), and Wake After Sleep Onset (WASO) the following night (12). These short-term associations were characterized by a small-tomoderate effect size. These experimental studies thus suggested a possible bidirectional association between sleep and physical activity outcomes. However, these findings were limited in terms of ecological validity (i.e., the behaviors were not measured in participants' daily life and over multiple days). 
In this perspective, previous studies investigated sleep - physical activity associations using ambulatory and daily measures and indicated that these two behaviours exhibited day-to-day variations (14-17). Furthermore, repeated measures provide data to differentiate inter- and intra-individual variations (i.e., daily deviations from an individual's usual behavior). Consequently, a better understanding of inter- and intra-individual associations between sleep and physical activity could be developed.

The daily associations between sleep and physical activity have been examined in observational or interventional contexts with self-report or objective measures (e.g., sleep device, pedometer). An observational study used 7-day accelerometer data to examine the bidirectional association between sleep and physical activity in women with breast cancer (13) and found an unidirectional association. The lower WASO, Total Wake Time (TWT), and TST (at intra-individual level) on the previous night was significantly related to a higher daily physical activity the next day within-participants. However, no significant relationships were found at the inter-individual level (e.g., participants with a higher level of physical activity did not report significantly different sleep parameters than participants with lower physical activity level, 13). Another observational study asked depressed and pair-matched nondepressed participants to rate their sleep quality and duration and to wear an accelerometer for 30-day. Only one directional association was significant. The higher sleep quality was related to higher physical activity the following day within participants and between participants.

Other studies with repeated daily measures examined these associations with different sleep physical activity measures or characterization, and tested unidirectional or bidirectional associations. For instance, Bittner et al. (14) analyzed the unidirectional association between sleep parameters and physical activity the following day. Gabriel et al. (15) explored bi-directional associations between selfreported sleep parameters and several physical activity outcomes (e.g., moderate and vigorous physical activity, light physical activity). These methodological features do not facilitate a clear understanding of daily associations between sleep and physical activity. Moreover, a different pattern of associations was observed at the inter- and intra-individual level. Despite the evidence supporting the short-term associations between these two behaviors, it is currently unclear if these associations are empirically validated in an ecological context. A better understanding of short associations between sleep and physical activity could provide useful information for the development of future interventions and theoretical refinement (16).

The primary goal of the current systematic review and meta-analysis was to summarize existing evidence about daily associations between sleep and physical activity outcomes at inter- and intra-individual level in adults. 


\section{Methods}

The systematic review and meta-analysis were conducted following the (Preferred Reporting Items for Systematic Reviews and Meta-Analyses guidelines) (17). The study protocol was registered in PROSPERO (CRD42019132662) and all the study materials and data are on Open Science Framework (available at https://osf.io/w6uy5/).

\section{Eligibility criteria}

In order to be included, studies must have: adult humans aged 18 (without a maximum age limitation); assessed sleep and physical activity with daily repeated measures; reported original empirical findings based on quantitative analysis of repeated daily lagged associations between sleep and physical activity, and be published articles in French or English. Studies also needed to have measured (objectively or self-reported) at least one of the following parameters for sleep: sleep quality, sleep parameters (SOL, TST, WASO, SE, sleep fragmentation, time in bed) and rapid eye movement; and for physical activity: daily time spent in light, moderate, vigorous physical activity, physical activity in different domains (leisure, household, active travel, work), training load, rated perceived exertion during physical exercise. Observational and interventional studies were included. Exercise interventions were considered eligible if they included aerobic, resistance or a combination of both. Studies were excluded if: they included children or teenagers in their sample (18), were qualitative studies, reviews, comments, opinion papers, practice or protocol recommendations, letters, and conference abstracts; had a retrospective design or performed only correlational analysis $(19,20)$.

\section{Search and Study Selection}

We conducted online research in the following databases: Pubmed/Medline, CINAHL, SPORTDiscus, PsycINFO, Academic Search Complete, ERIC, Psychology, and Behavioral Sciences Collection, for relevant publications up to June 2019. To reduce the risk of publication bias, two databases dedicated to grey literature were used (Open Grey and ProQuest Dissertations) (21). Furthermore, to find unpublished studies, we used two additional strategies. First, we contacted the sleep research societies (Canadian Sleep Society, Canadian Sleep and Canadian network, French Society of Sleep Medicine) ask them to share our documents request in their respective email lists and social network accounts. Second, we e-mailed the first authors of the included published papers to know whether they possessed any unpublished data or were aware of unpublished studies by other researchers. Studies were also sourced from three relevant systematic reviews (see PROSPERO for references). 
The search strategy was adapted for each database using its specific vocabulary map, employing Mesh terms that referred to "daily measures", "sleep" and "exercise". More details about search strategy are available in supplementary files. Titles and abstracts of the initially identified articles were scanned by five reviewers for exclusion criteria (CK, JP, AR, SA, PB). Then, full-text articles were screened by $\mathrm{CK}$ and PB. Any discrepancies were identified and resolved by the first author (SA).

\section{Data Collection Process}

Data were extracted on a pre-piloted spreadsheet by one author (SA) and cross-checked by two authors (SA, PB, GC). All relevant studies were scrutinized to extract the following data:

(a) Participants' characteristics and study design: year, country, number of participants randomly assigned, demographics, study duration, chronic disease, mental illness, control condition, sampling interval (interval-contingent, signal-contingent, and event-contingent recordings) and special design features;

(b) Outcomes: primary outcome, daily assessment measures, outcome characterization for physical activity and sleep;

(c) Statistical analysis: the direction of the association (physical activity --> sleep; sleep --> physical activity), type of statistical analysis, variability presence (between-person, within-person), control variables included in multivariate models.

(d) Findings from univariate or multivariate tested associations between physical activity and sleep outcomes.

(e) Risk of bias: 11 items adapted from Konjarski et al. (22) examined study aims, population, exclusion and inclusion criteria, statistic analyses, sleep, and physical activity measures.

\section{Data synthesis and analysis}

Following the recommendation of Guidance on the Conduct of Narrative Synthesis in Systematic Reviews (23), a narrative description of the included studies presented.

\section{Statistical Analyses}

The effect sizes were computed with Meta-Essentials (24). Given that regression coefficients are sensitive to the inclusion of control variables between studies, we conducted a meta-analysis on (semi) partial correlation coefficients because the coefficient is adjusted on the number of included variables in the model. Consequently, the r-to-z transformation was automatically applied. When means and standard deviations were not reported in the publication, authors were contacted to request missing 
information. When the information was not provided, the effect size could not be calculated and these studies were therefore excluded from the meta-analysis.

To quantify the associations between sleep and physical activity, a set of multilevel meta-analyses was performed because multiple measures of these behaviors are expected within the same study (e.g., physical activity characterized in terms of light physical activity and moderate and vigorous physical activity) (25). Indeed, several effects within studies violate assumptions of independence and might introduce error into effect size calculations (27). An association was tested when minimally three effects size for a sleep outcome were available. The physical activity outcomes were pooled together to decrease the beta risk. For instance, if the relationships between the time spent in light physical activity and the daily number of steps with SOL were examined in two different studies, they were pooled in one meta-analysis examining physical activity association (all different outcomes) with SOL. The associations at the inter- and intra-individual level were tested separately.

\section{Sensitivity Analyses}

A set of sensitivity analyses based on Robust Variance Estimation (26) was carried out following the recommendations provided by Quintana (27). All analyses were carried out in R 3.6 using the metafor and robumeta packages $(28,29)$.

\section{Results}

\section{Study selection}

The initial electronic searches identified 1666 references, of which 232 were duplicates. After a review of titles and abstracts, 1384 were excluded because they did not meet all inclusion criteria. Hence, 50 full-text articles were assessed for eligibility, and 12 were further included in the review. Twenty-one additional studies were identified through hand search of relevant articles, for a total of 33 articles (see Figure 1).

\section{Studies' Characteristics}

\section{Participants}

Table 1 summarizes the studies' characteristics (i.e., description of the sample, methods measuring physical activity and sleep). Across the 33 unique studies, 14,387 participants were included. Eleven studies (33\%) included exclusively women (13,15,30-38). Sample sizes ranged from 7 (39) to 10,086 (15) participants. Eight studies (24\%) included adults with sleep disturbances (e.g., insomnia) (38-45). Three (9\%) investigations included adults with mental disorders such as major depressive disorder and bipolar disorder $(40,45,46)$. 
Sleep and physical activity daily associations

\section{Location and setting}

Most studies were conducted in the United States of America, six in Europe, and three in Canada. The daily measures ranged from 5 to 196 days. Four studies examined the effect of supervised exercise intervention $(37,38,47,48)$. More details about the exercise interventions are available in the supplementary file.

\section{Sleep and physical activity measures}

Four studies exclusively used self-reported sleep and physical activity measures $(33,47,49,50)$. The two behaviors were exclusively objectively assessed in 10 studies $(13,31,32,37,41,42,46,48,51,52)$. Among the included studies, eight combined self-reported, and objective measures of sleep parameters $(14,30,38,45,53-56)$. All measures are detailed in Table 1.

\section{Statistical analyses carried out}

Over half of the studies (19 studies) examined a unidirectional temporal sequence between sleep and physical activity $(14,19,20,30,36,37,39,42,44,48,50,52,53,55,57,58,60-62)$. Conversely, the 14 other studies investigated the bidirectional associations. Mixed linear models were carried out in 23 studies. Details about statistical analyses are in the supplementary file (Table S1).

\section{Risk of bias assessments}

Two independent reviewers assessed the risk of bias for each included study. None of the 33 studies have a sample size justification or reported the commitments of the protocol. Besides, eleven of the included studies disregard to statistically lagged value of sleep and/or for the physical activity that is, sleeps parameters in the previous night or the levels of physical activity in the previous day to estimate the effect of autoregression. Three out of the 33 did not report the confounding variables statistically adjusted (see details in Figure 2).

Sleep measures temporally associated with physical activity the following day

Twenty-four studies examined this association (Table 2). Among them, seven did not find a significant association between sleep parameters and physical activity $(32-34,41,42,48,54)$.

Sleep onset latency. Among the eleven studies, only one study found a significant association between SOL and physical activity at the intra-individual level (38). High SOL was associated with low physical activity the following day. Otherwise, no other significant associations were found either for total physical activity $(13,35,41,52,55,56)$, moderate to vigorous physical activity $(13,32,35,47,54)$, or light physical activity (34).

Wake time after sleep onset. Thirteen studies scrutinized the WASO - physical activity associations and 3 studies found a significant association. High WASO on a given night was significantly as- 
sociated with physical activity counts the next day in breast cancer patients with sleep disorders at the intra-individual level (13). This association was also found in adults with retinitis pigmentosa patients (14) or cystic fibrosis (52). No other significant associations were observed with other physical activity characteristics (i.e., moderate to vigorous physical activity $(31,32,38,42,47)$, physical activity counts $(41,45,51,56)$, and light, moderate, vigorous physical activity (34).

Total sleep time. TST - physical activity daily associations were investigated in 19 studies. A significant and negative association was found in six studies. High TST was related to low physical activity total physical activity $(13,51)$, and moderate to vigorous physical activity $(31,58)$ at intra-individual level, in four studies. The same pattern of association was found at the inter-individual level in four studies $(13,31,57,58)$. Twelve studies did not identify a significant association between TST and moderate to vigorous physical activity $(13,32,35,38,42,48,52,54)$, light, moderate or vigorous physical activity $(34,42)$ and total physical activity $(31,35,41,44,52)$ at intra- and/or inter-individual level. One study with elderly women suggests that short sleep duration, between 7 to 9 hours was associated with additional light physical activity the next day, while a long time in bed ( $>9$ hours) decreased the likelihood of engaging in moderate to vigorous physical activity the following day (15).

Total wake time. Four studies examined the TWT - physical activity association. High TWT was associated with reduced total physical activity in two studies at the intra-individual level $(13,45)$. Otherwise, no significant association was observed in the studies $(31,44)$.

Sleep quality. Sleep quality and physical activity associations were studied in ten studies. Four studies concluded that high sleep quality was associated with greater physical activity counts (40), moderate to vigorous physical activity (47), and total physical activity at intra-person (44) and interindividual level (14). No significant association was observed in the six other investigations $(33,38,39,48,55,57)$.

Fragmentation index. Five studies examined the Fragmentation index - physical activity associations. A significant and negative association with physical activity counts and moderate to vigorous physical activity the following day were found in two studies $(14,35)$ at the inter-individual level. Otherwise, no significant associations were found in the three other studies $(34,38,54)$.

Sleep efficiency. Twelve studies considered the SE - physical activity association. One study, conducted in elderly women (35), identified a significant positive association between SE and physical activity outcomes (moderate to vigorous physical activity and total physical activity) at the betweenperson level. The eleven other studies did not find a significant association between SE and moderate 
to vigorous physical activity and total physical activity the following day $(13,31,32,34,38,42,52,54,56)$ at the inter- and intra-individual levels.

\section{Physical activity measures temporally associated with sleep the following night}

Detailed findings of the 27 studies examining the daily association between physical activity outcomes and sleep parameters are in Table 3. Thirteen out of the 27 studies did not find a significant temporal relationship between physical activity and sleep $(30,32-34,37,38,40,48,49,57,59,60)$.

Total physical activity. Six studies investigated the association between total physical activity and the SOL parameter. A greater physical activity counts on a given day were significantly associated at the inter-individual level with an increase of the SOL in pregnant women (36) as well as a decrease of the SOL in two other studies $(41,53)$ in individuals with chronic obstructive pulmonary disease and spinal cord injury, respectively. Otherwise, in three other studies, no significant associations were observed with SOL $(13,35,49)$. Nevertheless, conflicting results were found between total physical activity - WASO association among the 8 included studies. Two indicated that greater physical activity counts were associated with greater WASO the following night at the intra-individual level (51) and at the intra- and inter-individual level (13). The six other studies did not indicate any significant association with WASO $(31,41,53,61)(59,60)$. A complex pattern of findings was observed about the total physical activity - TST association. Three studies found a positive association (at within-person level) $(13,31,62)$, three identified a negative association (at inter-individual level) $(35,41,53)$, and six included studies did not identify a significant association $(36,40,49,51,59,60)$.

Light physical activity. Two studies scrutinized the light physical activity - sleep outcomes associations and no significant association with SOL, WASO, TST, SE parameters, and FI was observed in one study (34). However, more daily time spent in light-intensity physical activities was significantly related to an increasingly higher probability to have a night ranged from 7 to 9 hours of TST (15).

Moderate to vigorous physical activity. Eleven studies did not observe a significant association between moderate to vigorous physical activity and $\operatorname{SOL}(32,34,35,37,45,47,13,54,30,38)$. Ten studies examined the moderate to vigorous physical activity - TST associations. No significant association was found in seven studies at the different individual levels $(30,31,13,32,37,38,48)$. However, a positive association was found only at the intra-individual levels in older adults (54). Conversely, results with older women (35), suggest that more minutes of moderate to vigorous physical activity were temporally associated with less TST across the week at the inter-individual levels. Further, participants classified in the $\geq 20 \mathrm{~min} \cdot \mathrm{d}-1$ of accumulated moderate to vigorous physical activity category was associated 
with a reduced likelihood of reporting short or long sleep that night at the inter-individual levels older women (15).

The results obtained from our narrative synthesis are summarized in Figure 2. The green and red arrows represent positive and negative associations, respectively and dash arrows figure a no significant association. The inter- and at intra-individual level associations were combined.

\section{Meta-Analysis of included studies}

Findings from the set of the multi-level meta-analysis are presented in Table 5. For each computed association, two meta-analysis techniques were performed to ensure robust results across metaanalytical technics. The number of computed effect sizes and different studies are also presented. Three significant temporal associations between sleep outcomes and physical activity were found on 22 tested. WASO was significantly associated with decreased physical activity $(r=-.15,95 \% \mathrm{CI}=-.31$ $-.00, p=.05)$ at the intra-individual level. The analyses also revealed that SE and sleep quality were significantly associated with an increase in physical activity the following day. SE was associated at the inter-individual level $(r=.09,95 \% \mathrm{CI}=.01-.18, p=.03)$ and sleep quality at intra-individual level $(r$ $=.35,95 \% \mathrm{CI}=.00-.07, p=.05)$. Among the tested associations between physical activity and sleep outcomes, high physical activity was associated with low TST the following night at inter-individual level $(r=-.05,95 \% \mathrm{CI}=-.09-.00, p=.05)$. In our sensitivity analyses, effect sizes were generally similar but the significance threshold varied (see details in Table 5) and the SOL - physical activity association varied in terms of effect size and significance.

\section{Discussion}

\section{Summary of Evidence}

This systematic review summarized the available empirical evidence on the daily, bidirectional relationship between physical activity and sleep outcomes in adults. To the best of our knowledge, this is the first systematic review to address this specific question. A total of 33 studies were included in the systematic review. Given that the effect of physical activity on sleep parameters in the general popula-

tion has received attention relatively recently, both RCTs and non-RCTs, as well as observational and interventional studies, were included.

Overall, the qualitative and quantitative analyses of included studies did not support a bidirectional daily association between sleep outcomes and physical activity. Furthermore, our study suggested the absence of a consistent unidirectional pattern of association between sleep and physical activity characteristics (figure 2). More granular results were found by distinguishing the inter- and intra-indi- 
vidual level in meta-analyses. More specifically, WASO and sleep quality were significantly positively and negatively associated with physical activity at the intra-individual level. SE was positively associated with physical activity at the inter-individual level.

These findings should be interpreted with caution because diverse methodological approaches have been used in included investigations. The behavioral measures and characterizations, study designs, and performed statistical analyses in each study had probably affected our results.

The type of measure of sleep and physical activity (i.e., objective or self-reported) could explain conflicting findings. The correlations between objective and self-reported measures are low for sleep and physical activity, respectively (63). For instance, the lack of concordance between subjective and objective sleep measures is a consistent result in adults with sleep disorders $(64,65)$. Moreover, selfreported physical activity measures are negatively affected by social desirability and recall bias (6466). Consequently, the associations between sleep - physical activity behaviors could widely vary. For instance, five studies exclusively used self-reported measures of TST, sleep quality, and accelerometer data of total physical activity/moderate to vigorous physical activity $(15,36,39,40,57)$ and vice versa $(34,58-60)$.

The sleep or physical activity characterizations could also modify the tested associations. If sleep monitors or diaries allow computing sleep parameters, it is more complex with physical activity. Indeed, commercial or scientific wearable devices used in included studies provided one or several physical activity outcomes: moderate to vigorous physical activity, daily steps, total physical activity, or daily counts. Based on their hypotheses, or to decrease the number of statistical analyses, the authors generally selected one physical activity characteristic. However, a significant association between total daily physical activity with a sleep parameter could be explained by the proportion of time spent in moderate to vigorous physical activity during the day. Sleep - physical associations may exist only for a threshold of activity level (e.g., > 40 minutes of daily physical activity with moderate intensity) or type (e.g., outdoor physical activity).

As recommended for longitudinal data analysis (67), mixed linear models were carried out in two-thirds of included studies. However, most of the investigators did not consider the dependent variable autocorrelation in their models. For instance, Bernard et al. included previous night SE as a covariate in his model examining physical activity - SE association. Furthermore, the models' specifications were very different. The following covariables were generally missing in tested models, although their respective associations with sleep and physical activity are established: weekday (68, 69), season $(70,71)$, and psychotropic use (72). 
The contradicted findings of this review could also suggest that sleep-physical activity associations should not be examined with a lag-1 (i.e., association with previous night or day) but with a higher lag between sleep and physical activity. Irish et al. found that lag-7 bivariate models had best-fit indices that lag-1 models to describe temporal associations between physical activity and sleep parameters (34). Indeed, possible accumulation effect, social or hormonal rhythms have been proposed in studies examining behavioral circadian rhythm (73).

The different relationships between sleep and physical activity found at intra- and inter-individual level also suggests that these associations and their directions could be an idiosyncratic phenomenon, i.e., that differs in magnitude and direction from one person to another (74). Previous studies examining the daily associations between sleep or physical activity with another bio- or psychological variable revealed a different pattern of association at the group and individual level but also a causal heterogeneity (75-77). A study investigating the daily relationships between stress and physical activity shows that, on average, stress on one day was significantly associated with reduced physical activity the following day (75). This association was found in only 17/61 participants at the individual level. The examination of temporal daily relationships between TST and depressive symptoms showed that unidirectional associations could be positive, negative, or not significant at the idiographic level (77).

Finally, the sleep - physical activity daily associations could be mediated by exogeneous variables associated with a context or clinical features such as light exposition (78), physical fitness (79), hot flashes frequency $(80,81)$ who are respectively related to both, sleep and physical activity.

\section{Future Directions}

To develop a full picture of sleep and physical activity daily associations, additional studies will be needed. Future studies should assess these behaviors during minimally 12 consecutive days to examine different lagged associations. The first night of sleep monitoring is generally not represented in the ecological context, then missing data is the rule even if the adherence rate is generally good (i.e., $>80 \%$ ), and sleep parameters are modified during the weekend nights.

A combination of self-reported and device measures are recommended to examine sleep and physical activity behaviors (82). Except for perceived sleep quality, the statistical analyses between self-reported and objective measures should be avoided.

Nomothetic and idiographic statistical analyses should be carried out to verify that the results obtained at the group level match the ones obtained at the idiographic level (86). For instance, individual vector auto-regressive modeling allows the comparison of different lagged associations and facilitates Granger causality tests to explore bidirectional associations at the individual level, for each partic- 
ipant separately (see an example here (77), and tutorial (83)). It is important to note that these models require long time series ( $>50$-time points or days of observation), hence might be difficult to realize.

Future interventional studies should combine ambulatory daily assessment of sleep and physical activity pre- and post-intervention to compare the effects of treatment for sleep disorders or exercise interventions on the possible associations between these behaviors (84). The single case experimental studies combined with ecological momentary assessment could also provide more granular findings of the effects of an intervention on sleep-physical associations (85)

Finally, a future individual data participant meta-analysis could provide a fine analysis of sleep - physical activity associations and identify potential moderators (87). Thus, investigators in sleep medicine and physical activity sciences should strengthen their data sharing practices.

\section{Strengths and Study Limitations}

This study is the first to systematically and specifically review the literature on daily associations between sleep and physical activity in adults and to quantify these relationships in a meta-analysis. Conclusions from the present meta-analysis should be tempered by several limitations. First, our decision to pool all physical activity variables in meta-analyses could conceal existing associations between sleep parameters and different types (e.g., aerobic) or intensity of physical activity (88). Second, a selection bias could affect our quantitative findings because the number of studies in our meta-analyses was relatively small in comparison to the 33 included studies. Third, we included investigations with good and poor sleepers. Thus, our findings could be modified according to the presence of sleep disorders because poor sleepers generally have a lower level of physical activity (89).

\section{Conclusion}

Our systematic reviews of literature, combined with the meta-analyses, revealed that sleep parameters and physical activity were, overall, not significantly associated at the individual level. The different methodological approaches to measure these behaviors and examine their relationships were an important barrier to draw a general perspective about sleep and physical activity daily associations. Future studies should systematically explore these patterns of the association at inter- and intra-individual levels and investigate these behaviors at the idiographic level. 
Sleep and physical activity daily associations

Figure 1: Flowchart of the search results

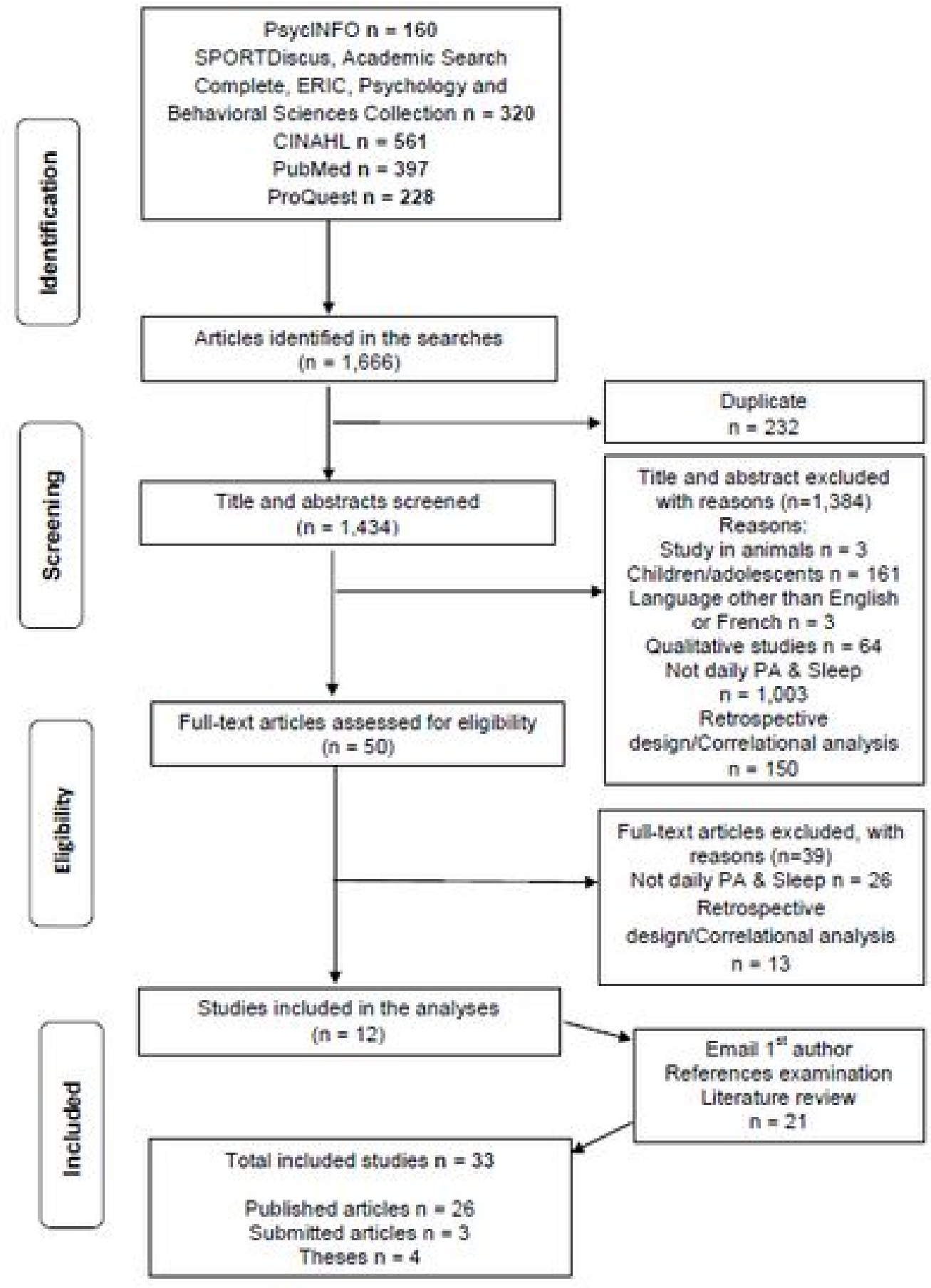


Sleep and physical activity daily associations

Figure 2. Summary of narrative review findings

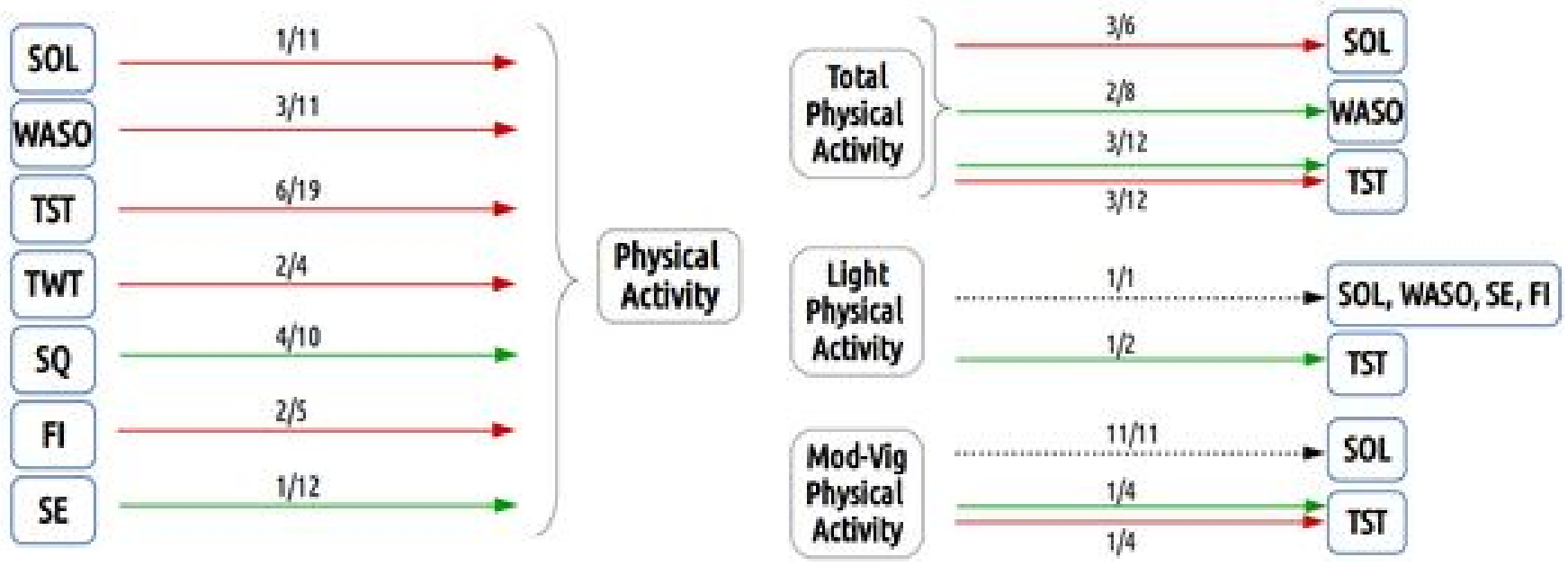

Notes. The green and red arrows represent positive and negative associations, respectively and dash arrows figure a no significant association. The inter- and at intra-individual level associations were combined. 
Sleep and physical activity daily associations

Table 1: Details of the included studies

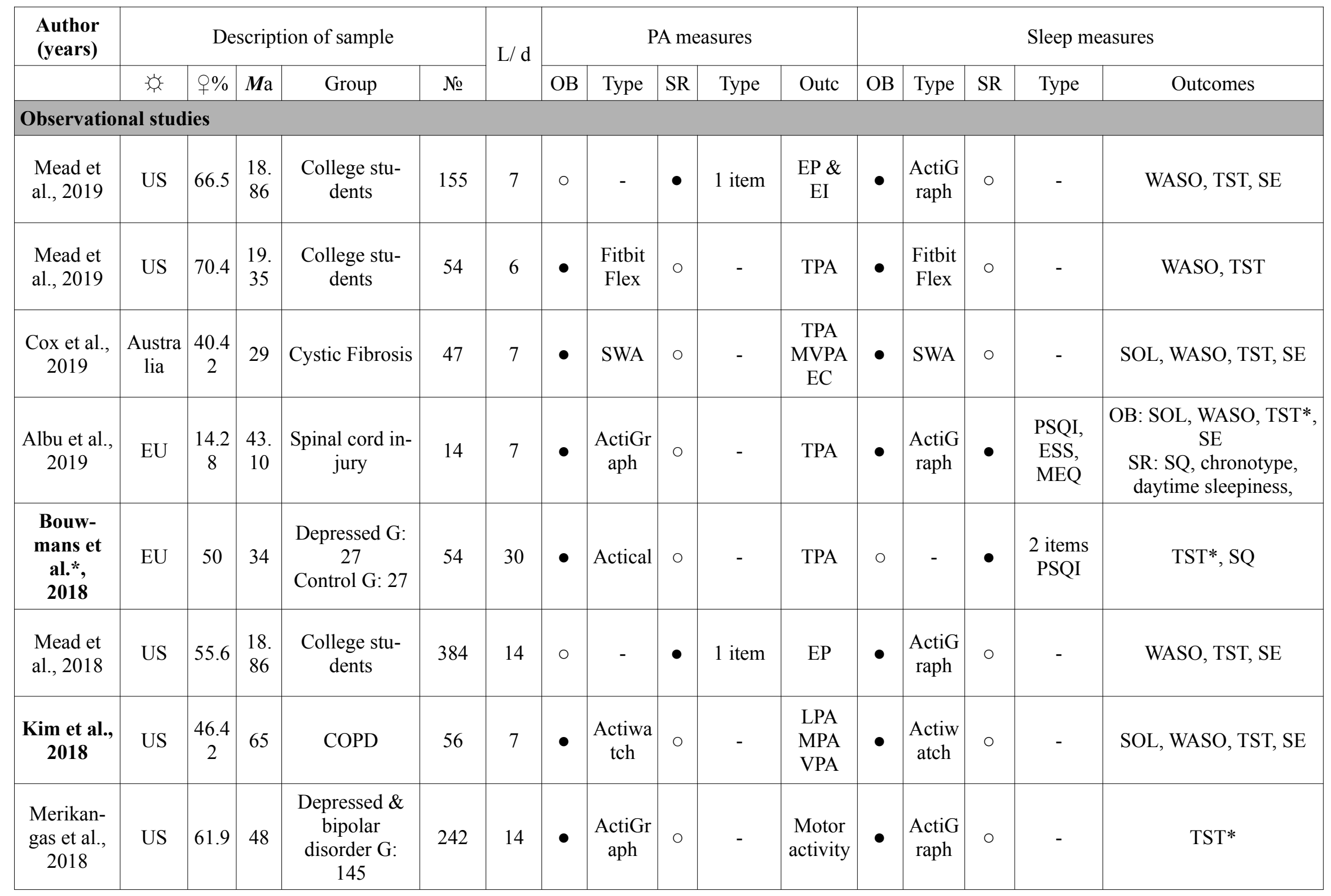


Sleep and physical activity daily associations

\begin{tabular}{|c|c|c|c|c|c|c|c|c|c|c|c|c|c|c|c|c|}
\hline & & & & Control G: 97 & & & & & & & & & & & & \\
\hline $\begin{array}{l}\text { Bittner et } \\
\text { al., } 2018\end{array}$ & US & 48.5 & 54 & $\begin{array}{c}\text { Retinitis } \\
\text { pigmentosa } \\
\text { patients }\end{array}$ & 33 & 7 & $\bullet$ & $\begin{array}{c}\text { Actiwa } \\
\text { tch }\end{array}$ & ○ & - & TPA & $\bullet$ & $\begin{array}{l}\text { Actiw } \\
\text { atch }\end{array}$ & $\bullet$ & $\begin{array}{l}\text { Sleep } \\
\text { diary }\end{array}$ & $\begin{array}{l}\text { OB: FI, WASO } \\
\text { SR: SQ }\end{array}$ \\
\hline $\begin{array}{c}\text { John R. } \\
\text { Best et al., } \\
2018\end{array}$ & $\begin{array}{c}\text { Canad } \\
\mathrm{a}\end{array}$ & 67 & 71 & & 152 & 14 & $\bullet$ & $\begin{array}{c}\text { ActiGr } \\
\text { aph }\end{array}$ & ○ & - & MVPA & $\bullet$ & $\begin{array}{l}\text { ActiG } \\
\text { raph }\end{array}$ & $\bullet$ & CSD & $\begin{array}{c}\text { OB: } \\
\text { SOL, SE, FI, TST } \\
\text { SR: } \\
\text { Bedtime, TST, TWT, SQ }\end{array}$ \\
\hline $\begin{array}{l}\text { Spina et } \\
\text { al., } 2018\end{array}$ & UK & 34 & $\begin{array}{c}66 . \\
4\end{array}$ & COPD & 932 & 6 & $\bullet$ & SWA & $\circ$ & - & $\begin{array}{c}\text { LPA } \\
\text { MVPA }\end{array}$ & $\bullet$ & SWA & ○ & - & WASO, TST, SE \\
\hline $\begin{array}{l}\text { McDonald } \\
\text { et al., } 2017\end{array}$ & UK & $\begin{array}{c}71.4 \\
2\end{array}$ & $\begin{array}{c}65 . \\
5\end{array}$ & $\begin{array}{l}\text { Approaching } \\
\text { retirement }\end{array}$ & 7 & $\begin{array}{l}87- \\
196\end{array}$ & $\bullet$ & $\begin{array}{l}\text { Tri- } \\
\text { axial }\end{array}$ & $\circ$ & - & TPA & ○ & - & $\bullet$ & $\begin{array}{l}\text { Sleep } \\
\text { diary }\end{array}$ & TST, SQ \\
\hline $\begin{array}{l}\text { Murray et } \\
\text { al., } 2017\end{array}$ & US & 100 & 55 & $\begin{array}{l}\text { Multiple } \\
\text { chronic } \\
\text { diseases }\end{array}$ & 377 & 5.5 & $\bullet$ & $\begin{array}{c}\text { ActiGr } \\
\text { aph }\end{array}$ & O & - & $\begin{array}{l}\text { MVPA } \\
\text {, out } \\
\text { doors } \\
\text { time }\end{array}$ & $\bullet$ & $\begin{array}{c}\text { ActiG } \\
\text { raph }\end{array}$ & $\bullet$ & $\begin{array}{l}\text { Sleep } \\
\text { diary }\end{array}$ & $\begin{array}{c}\text { OB: SOL, WASO, TST, } \\
\text { SE }\end{array}$ \\
\hline $\begin{array}{l}\text { Knufinke } \\
\text { et al.*, } \\
2017\end{array}$ & $\mathrm{EU}$ & 57 & 23 & Elite athletes & 98 & 7 & $\circ$ & - & $\bullet$ & $\begin{array}{l}\text { Diary } \\
\text { ratings }\end{array}$ & $\begin{array}{c}\text { training } \\
\operatorname{load}^{*}\end{array}$ & $\bullet$ & $\begin{array}{c}\text { ActiG } \\
\text { raph }\end{array}$ & O & - & $\begin{array}{l}\text { SOL, WASO, TST*, SE, } \\
\text { FI \& Sleep stages }\end{array}$ \\
\hline $\begin{array}{l}\text { Pettee et } \\
\text { al.*, } 2017\end{array}$ & US & 100 & 71 & & 10086 & 7 & $\bullet$ & $\begin{array}{c}\text { ActiGr } \\
\text { aph }\end{array}$ & $\bullet$ & $\begin{array}{l}\text { Diary of } \\
\text { leisure } \\
\text { time }\end{array}$ & $\begin{array}{l}\text { MVPA } \\
\text { LPA }\end{array}$ & O & - & $\bullet$ & $\begin{array}{l}\text { Sleep } \\
\text { diary }\end{array}$ & $\mathrm{TST}^{*}$ \\
\hline $\begin{array}{c}\text { Bernard } \\
\text { et al., } 2016\end{array}$ & $\begin{array}{c}\text { Canad } \\
\mathrm{a}\end{array}$ & 100 & 52 & $\begin{array}{l}\text { Breast cancer } \\
\text { patients }\end{array}$ & 66 & 7 & $\bullet$ & $\begin{array}{c}\text { Actiwa } \\
\text { tch }\end{array}$ & ○ & - & $\begin{array}{c}\text { MVPA } \\
\text { TPA }\end{array}$ & • & $\begin{array}{l}\text { Actiw } \\
\text { atch }\end{array}$ & O & - & $\begin{array}{c}\text { SOL, WASO, TST, } \\
\text { TWT, SE }\end{array}$ \\
\hline $\begin{array}{l}\text { Kishida et } \\
\text { al, } 2016\end{array}$ & US & 100 & 53 & & 103 & 21 & $\bullet$ & $\begin{array}{c}\text { ActiGr } \\
\text { aph }\end{array}$ & $\circ$ & - & MVPA & $\bullet$ & $\begin{array}{c}\text { ActiG } \\
\text { raph }\end{array}$ & 0 & - & WASO, TST, TWT*, SE \\
\hline $\begin{array}{l}\text { Fanning et } \\
\text { al., } 2016\end{array}$ & US & 75 & 20 & & 33 & 7 & $\bullet$ & $\begin{array}{c}\text { ActiGr } \\
\text { aph }\end{array}$ & 0 & - & MVPA & 0 & - & $\bullet$ & $\begin{array}{l}2 \text { items } \\
\text { PSQI }\end{array}$ & $\mathrm{TST}^{*}, \mathrm{SQ}$ \\
\hline $\begin{array}{l}\text { Mitchell et } \\
\text { al., } 2016\end{array}$ & US & 100 & 53 & $\begin{array}{l}\text { Sedentary \& } \\
\text { overweight }\end{array}$ & 353 & 7 & $\bullet$ & $\begin{array}{c}\text { ActiGr } \\
\text { aph }\end{array}$ & $\circ$ & - & MVPA & $\bullet$ & $\begin{array}{c}\text { ActiG } \\
\text { raph }\end{array}$ & 0 & - & SOL, WASO, TST, SE \\
\hline $\begin{array}{l}\text { Whitehead } \\
\text { et al., } 2016\end{array}$ & US & 74 & 79 & & 127 & 14 & 0 & - & $\bullet$ & $\begin{array}{c}\text { Diary } \\
\text { ratings* }\end{array}$ & $\begin{array}{l}\text { AP } \\
\text { AT }\end{array}$ & O & - & $\bullet$ & $\begin{array}{l}\text { Sleep } \\
\text { diary }\end{array}$ & SQ \\
\hline
\end{tabular}


Sleep and physical activity daily associations

\begin{tabular}{|c|c|c|c|c|c|c|c|c|c|c|c|c|c|c|c|c|}
\hline & & & & & & & & & & & $\begin{array}{l}\text { EP } \\
\text { ET }\end{array}$ & & & & & \\
\hline $\begin{array}{l}\text { Fortier et } \\
\text { al.* } 2014\end{array}$ & $\begin{array}{c}\text { Canad } \\
\text { a }\end{array}$ & 100 & 42 & $\begin{array}{c}\text { Physically } \\
\text { active working }\end{array}$ & 63 & 14 & $\circ$ & - & $\bullet$ & RPE & MVPA & $\circ$ & - & $\bullet$ & $\begin{array}{l}\text { Likert- } \\
\text { type } \\
\text { scale }\end{array}$ & $\mathrm{SQ}^{*}$ \\
\hline $\begin{array}{c}\text { Tang et } \\
\text { al., } 2014\end{array}$ & UK & 74 & 46 & $\begin{array}{l}\text { chronic pain } \\
\text { patients }\end{array}$ & 119 & 7 & $\bullet$ & $\begin{array}{c}\text { ActiGr } \\
\text { aph }\end{array}$ & ० & - & TPA & $\bullet$ & $\begin{array}{c}\text { ActiG } \\
\text { raph }\end{array}$ & $\bullet$ & $\begin{array}{l}\text { Sleep } \\
\text { diary }\end{array}$ & $\begin{array}{c}\text { OB: SE } \\
\text { SR: SOL, WASO, TST, } \\
\text { TWT, SE }\end{array}$ \\
\hline $\begin{array}{c}\text { Irish et } \\
\text { al.* }^{*}, 2013\end{array}$ & US & 100 & 52 & $\begin{array}{c}72.9 \% \text { pre- or } \\
\text { early } \\
\text { perimenopausa } \\
1\end{array}$ & 303 & 29 & $\circ$ & - & $\bullet$ & $\begin{array}{l}\text { Diary } \\
\text { ratings }\end{array}$ & $\begin{array}{l}\text { LPA } \\
\text { MPA } \\
\text { VPA }\end{array}$ & • & $\begin{array}{c}\text { ActiG } \\
\text { raph }\end{array}$ & $\circ$ & - & $\begin{array}{c}\text { SOL, WASO, SE, FI, } \\
\text { TST }\end{array}$ \\
\hline $\begin{array}{l}\text { Booth et } \\
\text { al., } 2012\end{array}$ & US & $\begin{array}{c}56.2 \\
5\end{array}$ & 26 & \begin{tabular}{|c|} 
Parental \\
history of type \\
2 diabetes \\
\end{tabular} & 48 & 14 & $\bullet$ & Actical & $\circ$ & - & TPA & $\bullet$ & $\begin{array}{l}\text { Actiw } \\
\text { atch }\end{array}$ & $\bullet$ & 2 items & $\begin{array}{l}\text { OB: SOL, TST } \\
\text { SR: TST, SQ }\end{array}$ \\
\hline $\begin{array}{l}\text { Youngstedt } \\
\text { et al., } 2003\end{array}$ & US & 72 & $\begin{array}{c}22 . \\
9\end{array}$ & Students & 31 & 102 & $\circ$ & - & $\bullet$ & Diary & TPA & $\circ$ & - & $\bullet$ & Diary & SOL, WASO, SE, TST \\
\hline $\begin{array}{l}\text { Nodine et } \\
\text { al., } 2011\end{array}$ & US & 100 & 30 & $\begin{array}{l}\text { Pregnant } \\
\text { women }\end{array}$ & 29 & 7 & $\bullet$ & $\begin{array}{l}\text { Pedo- } \\
\text { meter }\end{array}$ & ○ & - & TPA & $\circ$ & - & $\bullet$ & Diary & $\begin{array}{l}\text { SOL, WASO, TST, } \\
\text { SQ }\end{array}$ \\
\hline \multicolumn{17}{|c|}{ Exercise program interventions } \\
\hline $\begin{array}{l}\text { Breneman } \\
\text { et al., } 2019\end{array}$ & US & 100 & 64 & $\begin{array}{c}\text { lower-dose } \\
\text { exercise group: } \\
24\end{array}$ & 51 & 14 & $\bullet$ & SWA & $\circ$ & - & MVPA & $\bullet$ & $\begin{array}{c}\text { ActiG } \\
\text { raph }\end{array}$ & o & - & SOL, WASO, TST* \\
\hline
\end{tabular}


Sleep and physical activity daily associations

\begin{tabular}{|c|c|c|c|c|c|c|c|c|c|c|c|c|c|c|c|c|}
\hline & & & & $\begin{array}{l}\text { exercise group: } \\
27\end{array}$ & & & & & & & & & & & & \\
\hline $\begin{array}{l}\text { Nelson et } \\
\text { al., } 2017\end{array}$ & US & 0 & $\begin{array}{c}32 . \\
5\end{array}$ & & 19 & 14 & $\bullet$ & AP & O & - & MVPA & $\bullet$ & SWA & O & - & TST, SQ \\
\hline $\begin{array}{l}\text { Dzierzews } \\
\text { ki et al.*, } \\
2014\end{array}$ & US & 83 & 63 & Sedentary & 79 & 126 & O & - & $\bullet$ & LTEQ & MVPA & O & - & $\bullet$ & $\begin{array}{l}\text { Sleep } \\
\text { diary }\end{array}$ & SOL, WASO, SQ \\
\hline $\begin{array}{l}\text { Baron et } \\
\text { al.*, } 2013\end{array}$ & US & 100 & 61 & Sedentary & 11 & 112 & $\bullet$ & $\begin{array}{l}\text { ActiGr } \\
\text { aph }\end{array}$ & O & - & $\begin{array}{l}\text { OB: } \\
\text { MVPA } \\
\text { SR: } \\
\text { ET* }^{*}\end{array}$ & $\bullet$ & $\begin{array}{c}\text { ActiG } \\
\text { raph }\end{array}$ & $\bullet$ & $\begin{array}{l}\text { Sleep } \\
\text { diary }\end{array}$ & $\begin{array}{c}\text { SR: bedtime, get up } \\
\text { time, WASO, SQ } \\
\text { OB: SOL, WASO, TST, } \\
\text { SE, FI }\end{array}$ \\
\hline
\end{tabular}

Abbreviation: Bold characters: represent studies reported data from participants with sleep complaints (diagnosis of insomnia or insomnia symptoms), *:

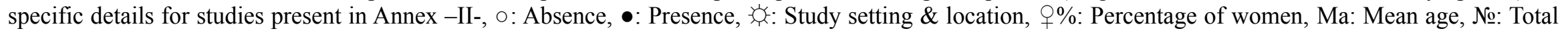
number of sample, L/ d: length of study per day, OB: Objective, SR: Self-Reported, Outc: Outcomes, US: United States , EU: Europe, UK: United Kingdom,

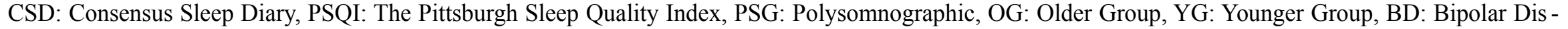

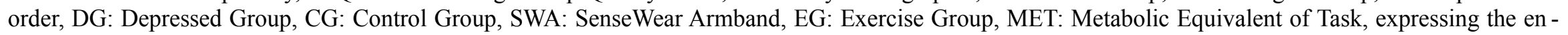
ergy cost of physical activity, AP: Activity Presence, AT: Activity Time, EP: Exercise Presence; EI: Exercise Intensity, EC: Exercise Capacity, LPA: Light Physical Activity, MPA: Moderate Physical Activity, VPA: Vigorous Physical Activity, MVPA: Moderate to Vigorous Physical Activity, LTEQ: Leisure-Time Exercise Questionnaire, RPE: Rating of Perceived Exertion, ET*: Exercise Time or exercise duration, SOL: Sleep Onset Latency, WASO: Wake After Sleep Onset, TST*: Total Sleep Time or sleep duration or time in bed, TWT*: Total Wake Time or awakening length, SE: Sleep Efficiency, FI: Fragmentation Index, SQ*: Sleep Quality or sleep satisfaction. 
Sleep and physical activity daily associations

Tableau 2: Sleep parameters predicting physical activity

\begin{tabular}{|c|c|c|c|c|c|c|c|c|}
\hline \multirow[t]{2}{*}{ Author } & \multicolumn{7}{|c|}{ Sleep parameters } & \multirow[t]{2}{*}{ PA } \\
\hline & SOL $\beta$ & WASO $\beta$ & TST $\beta$ & TWT $\beta$ & SQ $\beta$ & FI $\beta$ & SE $\beta$ & \\
\hline \multicolumn{9}{|c|}{ Observational studies } \\
\hline $\begin{array}{l}\text { Mead et } \\
\text { al., } 2019\end{array}$ & & & & & & & & EP\&EI \\
\hline $\begin{array}{l}\text { Mead et } \\
\text { al., } 2019\end{array}$ & & $\begin{array}{l}\text { WP } \\
\& \text { BP: } \\
\text { NS }\end{array}$ & $\begin{array}{l}\text { WP: }-2.75 \\
\text { BP: NS }\end{array}$ & & & & & TPA \\
\hline \multirow{3}{*}{$\begin{array}{c}\text { Cox et al., } \\
2019\end{array}$} & BP:NS & BP:- 1.0 & BP:NS & & & & BP:NS & TPA \\
\hline & BP:NS & BP:NS & BP:NS & & & & BP:NS & $\mathrm{EC}$ \\
\hline & BP:NS & BP:- .3 & BP:NS & & & & BP:NS & MVPA \\
\hline $\begin{array}{c}\text { Albu et } \\
\text { al., } 2019\end{array}$ & & & & & & & & TPA \\
\hline \multirow{2}{*}{$\begin{array}{c}\text { Bouw- } \\
\text { mans et } \\
\text { al., } \\
2018\end{array}$} & & & WP: .31 & & WP: .23 & & & \\
\hline & & & BP: - .21 & & BP: NS & & & TPA \\
\hline $\begin{array}{l}\text { Mead et } \\
\text { al., } 2018\end{array}$ & & OR: .991 & OR: .99 & & & & WP: NS & EP \\
\hline $\begin{array}{c}\text { Kim et al., } \\
2019\end{array}$ & BP:NS & BP:NS & BP:NS & & & & BP:NS & TPA \\
\hline $\begin{array}{l}\text { Merikan- } \\
\text { gas et al., } \\
2018\end{array}$ & & & -.027 & & & & & $\begin{array}{l}\text { Motor } \\
\text { activity }\end{array}$ \\
\hline $\begin{array}{l}\text { Bittner et } \\
\text { al., } 2018 \\
\end{array}$ & & BP: .12 & & & BP: .06 & BP: .21 & & TPA \\
\hline $\begin{array}{l}\text { Best et al., } \\
2018\end{array}$ & WP\&BP: NS & & WP\&BP: N & & & $\begin{array}{l}\text { WP } \\
\& \mathrm{BP}:\end{array}$ & $\begin{array}{l}\text { WP } \\
\& \mathrm{BP}:\end{array}$ & MVPA \\
\hline
\end{tabular}




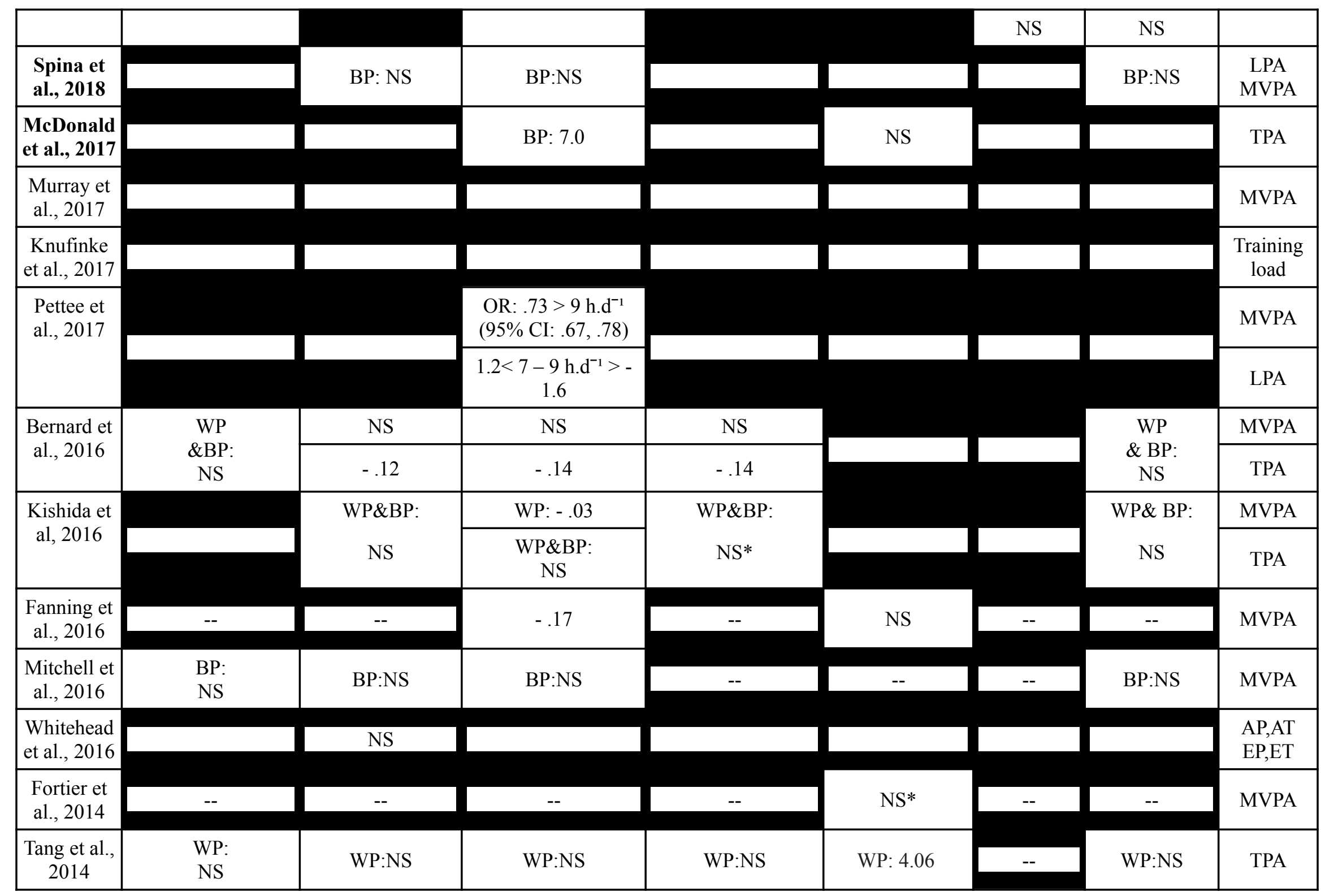


Sleep and physical activity daily associations

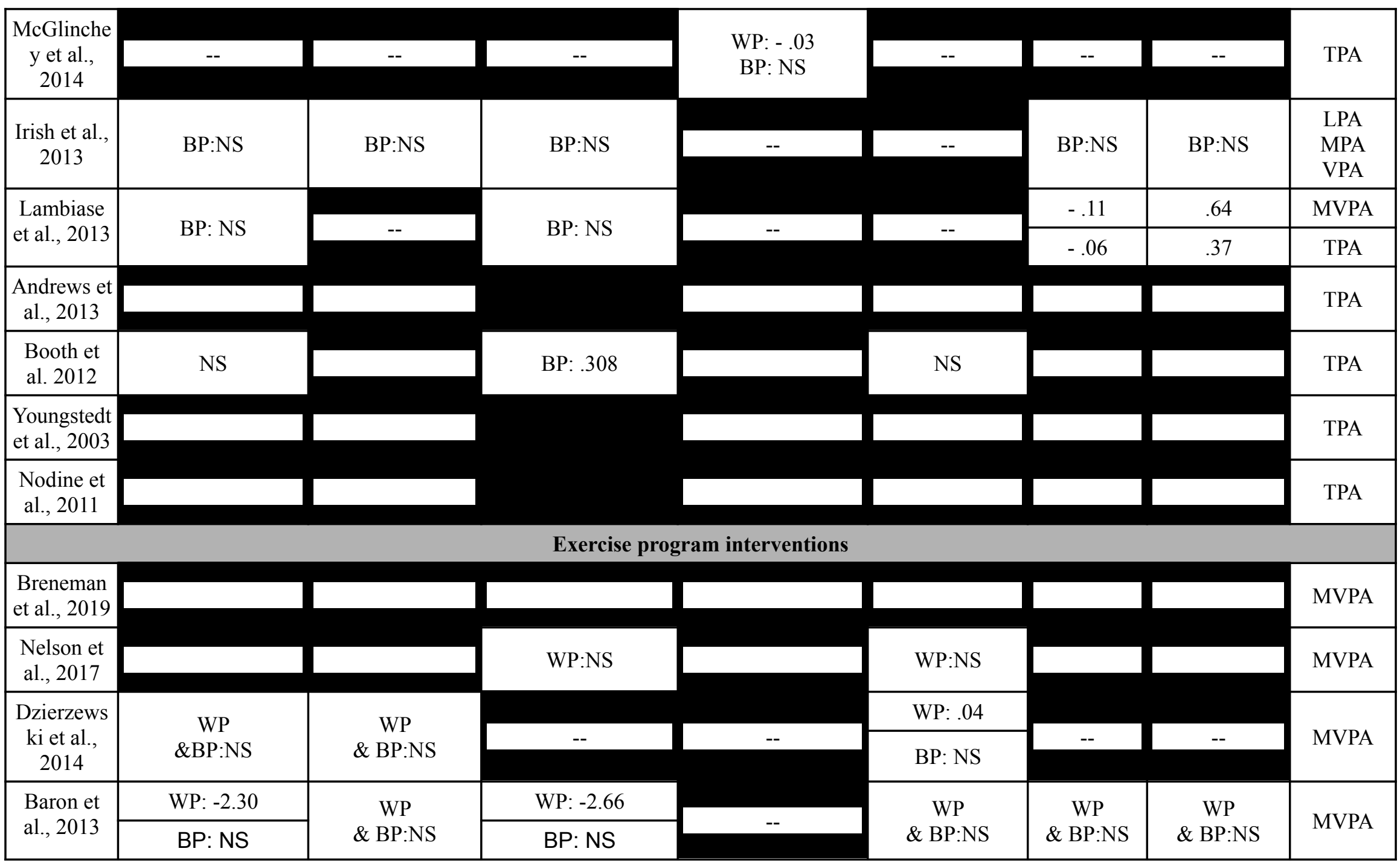

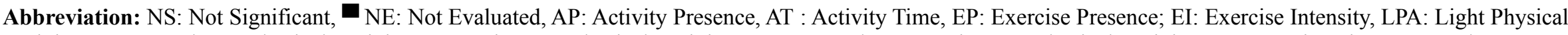
Activity, MPA: Moderate Physical Activity, VPA: Vigorous Physical Activity, MVPA: Moderate to Vigorous Physical Activity, ET: Exercise Time, SOL: Sleep Onset Latency, WASO: Wake After Sleep Onset, AL : Awakening Length, SS: Sleep Satisfaction, TWT: Total Wake Time, SE: Sleep Efficiency, TST: Total Sleep Time, SQ: Sleep Quality, FI: Fragmentation Index, AIC: Akiake Information Criterion, P: Relative Probability, OR: Odds Ratio, CI: Confidence Interval, h.d ${ }^{-1}$ : hours per day, BP: Between Person, WP: Within Person 
Sleep and physical activity daily associations

Table 3: Physical activity predicting sleep parameters

\begin{tabular}{|c|c|c|c|c|c|c|c|c|}
\hline Author & PA & & & & parame & & & \\
\hline & & SOL $\beta$ & WASO $\beta$ & TST $\beta$ & TWT $\beta$ & SE $\beta$ & FI $\beta$ & SQ B \\
\hline & & & & Observat & & & & \\
\hline $\begin{array}{l}\text { Mead et } \\
\text { al., } 2019\end{array}$ & EP \& EI & & WP: NS & WP: NS & & WP: NS & & \\
\hline $\begin{array}{l}\text { Mead et } \\
\text { al., } 2019\end{array}$ & TPA & & $\begin{array}{c}\text { WP: } 2.23 \\
\text { BP: NS }\end{array}$ & WP\&BP:NS & & & & \\
\hline $\begin{array}{c}\text { Cox et al., } \\
2019\end{array}$ & NE & & & & & & & \\
\hline $\begin{array}{c}\text { Albu et } \\
\text { al., } 2019\end{array}$ & TPA & $\begin{array}{c}\text { BP: - } \\
p=0.039\end{array}$ & BP: NS & $\begin{array}{c}\text { BP: - } \\
p=0.002\end{array}$ & & BP: NS & & \\
\hline $\begin{array}{c}\text { Bouw- } \\
\text { mans et } \\
\text { al., } \\
2018\end{array}$ & TPA & & & WP\&BP:NS & & & & WP\&BP:NS \\
\hline $\begin{array}{r}\text { Mead et } \\
\text { al., } 2018\end{array}$ & EP & & WP: NS & WP: NS & & WP: NS & & \\
\hline $\begin{array}{c}\text { Kim et al., } \\
2018\end{array}$ & TPA & BP: -.48 & BP: NS & BP: -.50 & & BP: NS & & \\
\hline $\begin{array}{l}\text { Merikan- } \\
\text { gas et al., } \\
2018\end{array}$ & $\begin{array}{l}\text { Motor } \\
\text { activity }\end{array}$ & & & -.154 & & & & \\
\hline $\begin{array}{l}\text { Bittner et } \\
\text { al., } 2018\end{array}$ & TPA & & & & & & & \\
\hline $\begin{array}{l}\text { John R. } \\
\text { Best et al., } \\
2018\end{array}$ & MVPA & $\begin{array}{c}\text { WP\&BP: } \\
\text { NS }\end{array}$ & & $\begin{array}{l}\text { WP: .01 } \\
\text { BP: NS }\end{array}$ & & $\begin{array}{c}\text { WP\&BP: } \\
\text { NS }\end{array}$ & $\begin{array}{c}\text { WP\&BI } \\
\text { NS }\end{array}$ & \\
\hline $\begin{array}{l}\text { Spina et } \\
\text { al., } 2018\end{array}$ & $\mathrm{NE}$ & & & & & & & \\
\hline
\end{tabular}


Sleep and physical activity daily associations

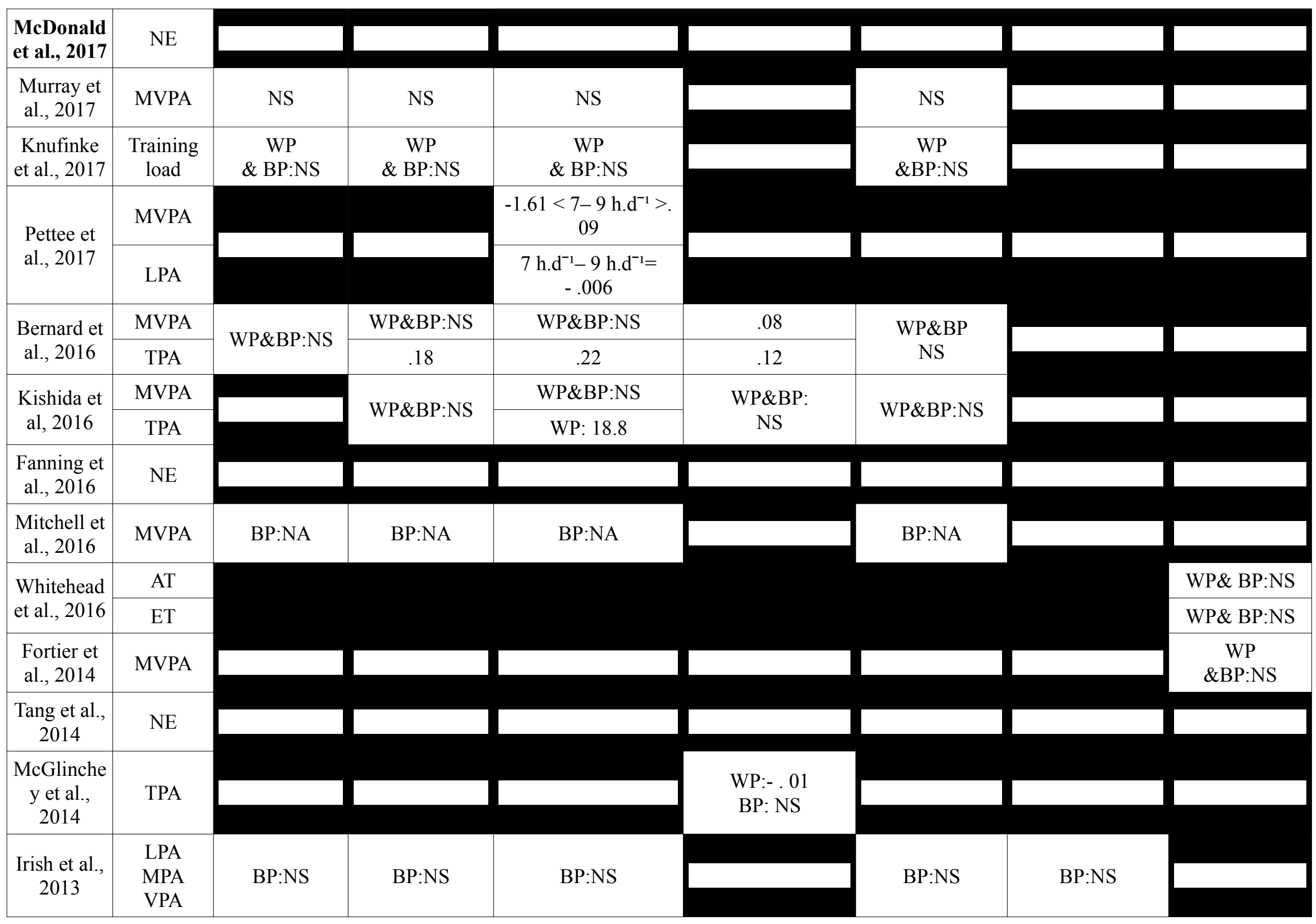


Sleep and physical activity daily associations

\begin{tabular}{|c|c|c|c|c|c|c|c|}
\hline \multirow{2}{*}{$\begin{array}{l}\text { Lambiase } \\
\text { et al., } 2013\end{array}$} & MVPA & \multirow{2}{*}{ NS } & & -.03 & \multirow{2}{*}{ NS } & \multirow{2}{*}{ NS } & \\
\hline & TPA & & & -.05 & & & \\
\hline $\begin{array}{c}\text { Andrews et } \\
\text { al., } 2013\end{array}$ & TPA & & & WP: .0002 & & & \\
\hline $\begin{array}{l}\text { Booth et } \\
\text { al., } 2012\end{array}$ & NE & & & & & & \\
\hline $\begin{array}{l}\text { Youngstedt } \\
\text { et al., } 2003\end{array}$ & TPA & WP\&BP:NS & WP\&BP:NS & WP\&BP:NS & WP\&BP:NS & & \\
\hline $\begin{array}{l}\text { Nodine et } \\
\text { al., } 2011\end{array}$ & TPA & BP: 2.102 & BP: NS & BP: NS & & & BP: -2.625 \\
\hline & & & & xercise progr & & & \\
\hline $\begin{array}{l}\text { Breneman } \\
\text { et al., } 2019\end{array}$ & MVPA & BP:NS & BP:NS & BP:NS & & & \\
\hline $\begin{array}{l}\text { Nelson et } \\
\text { al., } 2017\end{array}$ & MVPA & & & WP:NS & & & WP:NS \\
\hline Dzierzews & & NS & WP: NS & & & & WP: .06 \\
\hline 2014 & S & NS & BP: -.34 & & & & BP: NA \\
\hline $\begin{array}{l}\text { Baron et } \\
\text { al., } 2013\end{array}$ & MVPA & $\begin{array}{c}\text { WP } \\
\& \text { BP:NS }\end{array}$ & $\begin{array}{c}\text { WP } \\
\& \text { BP:NS }\end{array}$ & $\begin{array}{c}\text { WP } \\
\& \text { BP:NS }\end{array}$ & $\begin{array}{c}\text { WP } \\
\text { \&BP:NS }\end{array}$ & WP\& BP:NS & $\begin{array}{c}\text { WP } \\
\text { \&BP:NS }\end{array}$ \\
\hline
\end{tabular}

Abbreviation: NS: Not Significant, $\mathbf{n}$ : Not Evaluated, AP: Activity Presence, AT : Activity Time, EP: Exercise Presence; Ei: Exercise Intensity LPA: Light Physical Activity, MPA: Moderate Physical Activity, VPA: Vigorous Physical Activity, MVPA: Moderate to Vigorous Physical Activity, ET: Exercise Time, SOL: Sleep Onset Latency, WASO: Wake After Sleep Onset, AL : Awakening Length, SS: Sleep Satisfaction, TWT: Total Wake Time, SE: Sleep Efficiency, TST: Total Sleep Time, SQ: Sleep Quality, FI: Fragmentation Index, h.d $\mathrm{d}^{-1}$ : hours per day, BP: Between Person, WP: Within Person 


\section{PREPRINT}

Table 5 Results of meta-analyses

\begin{tabular}{|c|c|c|c|c|}
\hline Associations & Effect size & Effect size & $\mathbf{k}$ & Studies \\
\hline & WP & BP & $\mathbf{W P} / \mathbf{B P}$ & WB/BP \\
\hline \multicolumn{5}{|c|}{ SOL } \\
\hline \multirow{2}{*}{$\mathrm{SOL} \rightarrow \mathrm{PA}$} & $-.03(95 \% \mathrm{CI}=-.21-.14)$ & $-.22(95 \% \mathrm{CI}=-.59-.15, p=.20)$ & \multirow{2}{*}{$5 / 8$} & \multirow{2}{*}{$4 / 7$} \\
\hline & $-.03(95 \% \mathrm{CI}=-.27-.20)$ & $-.09(95 \% \mathrm{CI}=-.18--.00, p=.05)$ & & \\
\hline \multirow{2}{*}{$\mathrm{PA} \rightarrow \mathrm{SOL}$} & $.02(95 \% \mathrm{CI}=-.06-.11)$ & $-.04(95 \% \mathrm{CI}=-.11-.03)$ & \multirow{2}{*}{$7 / 9$} & \multirow{2}{*}{$7 / 7$} \\
\hline & $.02(95 \% \mathrm{CI}=-.19-.13)$ & $-.04(95 \% \mathrm{CI}=-.11-.04)$ & & \\
\hline \multicolumn{5}{|c|}{ WASO } \\
\hline \multirow{2}{*}{$\mathrm{WASO} \rightarrow \mathrm{PA}$} & $-.15(95 \% \mathrm{CI}=-.31-.00, p=.05)$ & $-.08(95 \% \mathrm{CI}=-.25-.08)$ & \multirow{2}{*}{$5 / 8$} & \multirow{2}{*}{$4 / 6$} \\
\hline & $-13(95 \% \mathrm{CI}=-.28-.02, p=.06)$ & $-0.07(95 \% \mathrm{CI}=-.02-.08)$ & & \\
\hline \multirow{2}{*}{$\mathrm{PA} \rightarrow \mathrm{WASO}$} & --- & $-.06(95 \% \mathrm{CI}=-.17-.06)$ & \multirow{2}{*}{$/ 9$} & \multirow{2}{*}{$/ 6$} \\
\hline & --- & $-.05(95 \% \mathrm{CI}=-.19-.08)$ & & \\
\hline \multicolumn{5}{|c|}{ TST } \\
\hline \multirow{2}{*}{$\mathrm{TST} \rightarrow \mathrm{PA}$} & $-.48(95 \% \mathrm{CI}=-1.73-.77)$ & $-.09(95 \% \mathrm{CI}=-.43-.24)$ & \multirow{2}{*}{$7 / 20$} & \multirow{2}{*}{$6 / 11$} \\
\hline & $-.02(95 \% \mathrm{CI}=-0.09-.13)$ & $-.08(95 \% \mathrm{CI}=-.36-.20)$ & & \\
\hline \multirow{2}{*}{$\mathrm{PA} \rightarrow \mathrm{TST}$} & $.08(95 \% \mathrm{CI}=-.11-.28)$ & $-.05(95 \% \mathrm{CI}=-.09-.00, p=.05)$ & \multirow{2}{*}{$8 / 22$} & \multirow{2}{*}{$7 / 12$} \\
\hline & $.07(95 \% \mathrm{CI}=-0.11-.28)$ & $-.04(95 \% \mathrm{CI}=-.09-.01, p=.13)$ & & \\
\hline \multicolumn{5}{|c|}{ TWT } \\
\hline \multirow{2}{*}{$\mathrm{TWT} \rightarrow \mathrm{PA}$} & $-.28(95 \% \mathrm{CI}=-.67-.10, p=.08)$ & --- & \multirow{2}{*}{$3 /$} & \multirow{2}{*}{$2 /$} \\
\hline & $-.26(95 \% \mathrm{CI}=-.38--.15, p=.02)$ & & & \\
\hline \multirow{2}{*}{$\mathrm{PA} \rightarrow \mathrm{TWT}$} & $-.23(95 \% \mathrm{CI}=-.35-.82)$ & --- & \multirow{2}{*}{$3 /$} & \multirow{2}{*}{$2 /$} \\
\hline & $-.21(95 \% \mathrm{CI}=-1.42-1.83)$ & & & \\
\hline \multicolumn{5}{|c|}{ FI } \\
\hline \multirow{2}{*}{$\mathrm{FI} \rightarrow \mathrm{PA}$} & --- & $-.15(95 \% \mathrm{CI}=-.32-.03)$ & \multirow{2}{*}{$/ 3$} & \multirow{2}{*}{$/ 2$} \\
\hline & --- & $-.13(95 \% \mathrm{CI}=-.58-.31)$ & & \\
\hline $\mathrm{PA} \rightarrow \mathrm{FI}$ & --- & $-.008(95 \% \mathrm{CI}=-.10-.09)$ & 15 & 14 \\
\hline
\end{tabular}




\section{PREPRINT}

\begin{tabular}{|c|c|c|c|c|}
\hline & --- & $-.008(95 \% \mathrm{CI}=-.19-.21)$ & & \\
\hline \multicolumn{5}{|c|}{ SE } \\
\hline \multirow{2}{*}{$\mathrm{SE} \rightarrow \mathrm{PA}$} & $.06(95 \% \mathrm{CI}=-.05-.17)$ & $.09(95 \% \mathrm{CI}=.01-.18, p=.03)$ & \multirow{2}{*}{$6 / 10$} & \multirow{2}{*}{$4 / 6$} \\
\hline & $.05(95 \% \mathrm{CI}=-.05-.15)$ & $.08(95 \% \mathrm{CI}=-.05-.21, p=.12)$ & & \\
\hline \multirow{2}{*}{$\mathrm{PA} \rightarrow \mathrm{SE}$} & $.03(95 \% \mathrm{CI}=-.09-.15)$ & $-.01(95 \% \mathrm{CI}=-.06-.03)$ & \multirow{2}{*}{$5 / 13$} & \multirow{2}{*}{$5 / 8$} \\
\hline & $.02(95 \% \mathrm{CI}=-.14-.18)$ & $-.02(95 \% \mathrm{CI}=-.07-.04)$ & & \\
\hline \multicolumn{5}{|c|}{ SQ } \\
\hline \multirow{2}{*}{$\mathrm{SQ} \rightarrow \mathrm{PA}$} & $.35(95 \% \mathrm{CI}=-.00-.70, p=.05)$ & $.04(95 \% \mathrm{CI}=-.27-.36)$ & $3 / 3$ & $3 / 3$ \\
\hline & $.32(95 \% \mathrm{CI}=-.03-.70, p=.06)$ & $.04(95 \% \mathrm{CI}=-.22-.31)$ & & \\
\hline \multirow{2}{*}{$\mathrm{PA} \rightarrow \mathrm{SQ}$} & --- & $-.09(95 \% \mathrm{CI}=-.53-.35)$ & $/ 4$ & $/ 4$ \\
\hline & --- & $-.07(95 \% \mathrm{CI}=-0.04-.31)$ & & \\
\hline
\end{tabular}

Notes. The second line of each tested association represents findings from sensitivity analyses.

SOL: Sleep Onset Latency, WASO: Wake After Sleep Onset, AL : Awakening Length, SS: Sleep Satisfaction, TWT: Total Wake Time, SE: Sleep Efficiency, TST: Total Sleep Time, SQ: Sleep Quality, FI: Fragmentation Index, h.d ${ }^{-1}$ : hours per day, BP: Between Person, WP: Within Person, $\mathrm{k}=$ number of available effect sizes. 


\section{PREPRINT}

\section{Conflicts of interest}

The authors have no conflict of interest to declare.

\section{Acknowledgements}

The authors would like to thank all the researchers who took part in the study for her help with the achievement of this work. They would also like to thank Adam Sanborn, Mara Bouwmans, Jonathan Mitchell, Fanning Jason, Leah Irish, Michael P. Mead, Laura Ellingson, Wang X, Matthew Buman, Joseph Dzierzewski, Kate Murray and Mary Kapella for sharing their findings. 


\section{PREPRINT}

\section{References}

1. Buysse DJ. Sleep health: can we define it? Does it matter? Sleep. 1 janv 2014;37(1):917.

2. Warburton DER, Bredin SSD. Reflections on Physical Activity and Health: What Should We Recommend? Can J Cardiol. avr 2016;32(4):495504.

*3. Chennaoui M, Arnal PJ, Sauvet F, Léger D. Sleep and exercise: a reciprocal issue? Sleep Med Rev. avr 2015;20:5972.

4. Youngstedt, Kline CE. Epidemiology of exercise and sleep. Sleep Biol Rhythms. août 2006;4(3):21521.

5. Kline CE. The bidirectional relationship between exercise and sleep: Implications for exercise adherence and sleep improvement. Am J Lifestyle Med. déc 2014;8(6):3759.

6. Semplonius T, Willoughby T. Long-Term Links between Physical Activity and Sleep Quality. Med Sci Sports Exerc. déc 2018;50(12):241824.

7. Rayward AT, Burton NW, Brown WJ, Holliday EG, Plotnikoff RC, Duncan MJ. Associations between Changes in Activity and Sleep Quality and Duration over Two Years. Med Sci Sports Exerc. déc 2018;50(12):2425.

8. Holfeld B, Ruthig JC. A longitudinal examination of sleep quality and physical activity in older adults. J Appl Gerontol Off J South Gerontol Soc. oct 2014;33(7):791807.

9. Bromley LE, Booth JN, Kilkus JM, Imperial JG, Penev PD. Sleep restriction decreases the physical activity of adults at risk for type 2 diabetes. Sleep. 1 juill 2012;35(7):97784.

10. Schmid SM, Hallschmid M, Jauch-Chara K, Wilms B, Benedict C, Lehnert H, et al. Short-term sleep loss decreases physical activity under free-living conditions but does not increase food intake under time-deprived laboratory conditions in healthy men. Am J Clin Nutr. déc 2009;90(6):147682.

11. Markwald RR, Melanson EL, Smith MR, Higgins J, Perreault L, Eckel RH, et al. Impact of insufficient sleep on total daily energy expenditure, food intake, and weight gain. Proc Natl Acad Sci U S A. 2 avr 2013;110(14):5695700.

12. Kredlow MA, Capozzoli MC, Hearon BA, Calkins AW, Otto MW. The effects of physical activity on sleep: a meta-analytic review. J Behav Med. 1 juin 2015;38(3):42749.

*13. Bernard P, Ivers H, Savard M-H, Savard J. Temporal relationships between sleep and physical activity among breast cancer patients with insomnia. Health Psychol. déc 2016;35(12):130715. 


\section{PREPRINT}

14. Bittner AK, Haythornthwaite JA, Patel C, Smith MT. Subjective and Objective Measures of Daytime Activity and Sleep Disturbance in Retinitis Pigmentosa. Optom Vis Sci Off Publ Am Acad Optom. 2018;95(9):83743.

15. Pettee Gabriel K, Sternfeld B, Shiroma EJ, Pérez A, Cheung J, Lee I-M. Bidirectional associations of accelerometer-determined sedentary behavior and physical activity with reported time in bed: Women's Health Study. Sleep Health. 2017;3(1):4955.

16. Borbély AA, Daan S, Wirz-Justice A, Deboer T. The two-process model of sleep regulation: a reappraisal. J Sleep Res. avr 2016;25(2):13143.

17. Moher D, Liberati A, Tetzlaff J, Altman DG. Preferred reporting items for systematic reviews and meta-analyses: the PRISMA statement. Ann Intern Med. 2009;151(4):2649.

18. Pesonen A-K, Sjöstén NM, Matthews KA, Heinonen K, Martikainen S, Kajantie E, et al. Temporal associations between daytime physical activity and sleep in children. PloS One. 2011;6(8):e22958.

19. Buman MP, Hekler EB, Bliwise DL, King AC. Exercise effects on night-to-night fluctuations in self-rated sleep among older adults with sleep complaints. J Sleep Res. mars 2011;20(1 Pt 1):2837.

20. Ready RE, Marquez DX, Akerstedt A. Emotion in younger and older adults: retrospective and prospective associations with sleep and physical activity. Exp Aging Res. sept 2009;35(3):34868.

21. Conn VS, Valentine JC, Cooper HM, Rantz MJ. Grey literature in meta-analyses. Nurs Res. 2003;52(4):25661.

22. Konjarski M, Murray G, Lee VV, Jackson ML. Reciprocal relationships between daily sleep and mood: A systematic review of naturalistic prospective studies. Sleep Med Rev. déc 2018;42:4758.

23. Popay J, Roberts H, Sowden A, Petticrew M, Arai L, Rodgers M, et al. Guidance on the conduct of narrative synthesis in systematic reviews. Prod ESRC Methods Programme Version. 2006;1:b92.

24. Suurmond R, van Rhee H, Hak T. Introduction, comparison, and validation of Meta-Essentials: A free and simple tool for meta-analysis. Res Synth Methods. 2017;8(4):53753.

25. Borenstein M, Hedges LV, Higgins JP, Rothstein HR. Introduction to meta-analysis. John Wiley \& Sons; 2011.

26. Hedges LV, Tipton E, Johnson MC. Robust variance estimation in meta-regression with dependent effect size estimates. Res Synth Methods. janv 2010;1(1):3965.

27. Quintana DS. From pre-registration to publication: a non-technical primer for conducting a metaanalysis to synthesize correlational data. Front Psychol [Internet]. 8 oct 2015;6. 


\section{PREPRINT}

28. Fisher Z, Tipton E. robumeta: An R-package for robust variance estimation in meta-analysis. ArXiv150302220 Stat [Internet]. 7 mars 2015; http://arxiv.org/abs/1503.02220

29. Viechtbauer W. Conducting Meta-Analyses in R with the metafor Package. J Stat Softw. 5 août 2010;36(1):148.

30. Murray K, Godbole S, Natarajan L, Full K, Hipp JA, Glanz K, et al. The relations between sleep, time of physical activity, and time outdoors among adult women. PloS One. 2017;12(9):e0182013.

31. Kishida M, Elavsky S. An intensive longitudinal examination of daily physical activity and sleep in midlife women. Sleep Health. mars 2016;2(1):428.

32. Mitchell JA, Godbole S, Moran K, Murray K, James P, Laden F, et al. No Evidence of Reciprocal Associations between Daily Sleep and Physical Activity. Med Sci Sports Exerc. oct 2016;48(10):19506.

33. Fortier MS, Guerin E, Williams T, Strachan S. Should I exercise or sleep to feel better? A daily analysis with physically active working mothers. Ment Health Phys Act. 1 mars 2015;8(Supplement C):5661.

34. Irish LA, Kline CE, Rothenberger SD, Krafty RT, Buysse DJ, Kravitz HM, et al. A 24-hour approach to the study of health behaviors: temporal relationships between waking health behaviors and sleep. Ann Behav Med. avr 2014;47(2):18997.

35. Lambiase MJ, Gabriel KP, Kuller LH, Matthews KA. Temporal relationships between physical activity and sleep in older women. Med Sci Sports Exerc. 2013;45(12):23628.

36. Nodine PM. The contribution of physical activity to sleep parameters in pregnancy within the context of prepregnant body mass index [Internet] [Ph.D.]. [Ann Arbor]: University of Colorado Health Sciences Center; 2011. Disponible à: https://search.proquest.com/docview/884225025? accountid=14719

37. Breneman CB. The effects of exercise on sleep parameters among older women [Internet] [Ph.D.]. [Ann Arbor]: University of South Carolina; 2016. Disponible à: https://search.proquest.com/docview/1865632206?accountid=14719

38. Baron KG, Reid KJ, Zee PC. Exercise to improve sleep in insomnia: exploration of the bidirectional effects. J Clin Sleep Med JCSM Off Publ Am Acad Sleep Med. 15 août 2013;9(8):81924.

39. McDonald S, Vieira R, Godfrey A, O'Brien N, White M, Sniehotta FF. Changes in physical activity during the retirement transition: a series of novel n-of-1 natural experiments. Int J Behav Nutr Phys Act. 8 déc 2017;14:112. 


\section{PREPRINT}

40. Bouwmans MEJ, Oude Oosterik NAM, Bos EH, de Groot IW, Oldehinkel AJ, de Jonge P. The Temporal Order of Changes in Physical Activity and Subjective Sleep in Depressed Versus Nondepressed Individuals: Findings From the MOOVD Study. Behav Sleep Med. avr 2018;16(2):15468.

41. Kim I. Sleep Disturbance and Physical Activity in Chronic Obstructive Pulmonary Disease [Ph.D.]. [Ann Arbor]: University of Illinois at Chicago; 2018. Disponible à: https://search.proquest.com/docview/2086088706?accountid=14719

42. Spina G, Spruit MA, Alison J, Benzo RP, Calverley PMA, Clarenbach CF, et al. Analysis of nocturnal actigraphic sleep measures in patients with COPD and their association with daytime physical activity. Thorax. 2017;72(8):694701.

43. Bernard P, Ivers H, Savard M-H, Savard J. Temporal relationships between sleep and physical activity among breast cancer patients with insomnia. Health Psychol. déc 2016;35(12):130715.

44. Tang NKY, Sanborn AN. Better Quality Sleep Promotes Daytime Physical Activity in Patients with Chronic Pain? A Multilevel Analysis of the Within-Person Relationship. PLoS ONE. mars 2014;9(3):19.

45. McGlinchey EL, Gershon A, Eidelman P, Kaplan KA, Harvey AG. Physical activity and sleep: Day-to-day associations among individuals with and without bipolar disorder. Ment Health Phys Act. 1 sept 2014;7(3):18390.

46. Merikangas KR, Swendsen J, Hickie IB, Cui L, Shou H, Merikangas AK, et al. Real-time mobile monitoring of the dynamic associations among motor activity, energy, mood, and sleep in adults with bipolar disorder. JAMA Psychiatry. 2019;76(2):1908.

*47. Dzierzewski JM, Buman MP, Giacobbi PR, Roberts BL, Aiken-Morgan AT, Marsiske M, et al. Exercise and Sleep in Community-Dwelling Older Adults: Evidence for a Reciprocal Relationship. J Sleep Res. févr 2014;23(1):618.

48. Nelson CL. The relationship between sleep and sedentary time, and the impact of varying sleep patterns [Internet] [Master of Science]. [Ames]: Iowa State University, Digital Repository; 2017. p. 11457119. Disponible à: https://lib.dr.iastate.edu/etd/16183/

49. Youngstedt SD, Perlis ML, O'Brien PM, Palmer CR, Smith MT, Orff HJ, et al. No association of sleep with total daily physical activity in normal sleepers. Physiol Behav. 2003;78(3):395401.

50. Whitehead BR, Blaxton JM. Daily Well-Being Benefits of Physical Activity in Older Adults: Does Time or Type Matter? The Gerontologist. 10 2017;57(6):106271.

51. Mead MP, Baron K, Sorby M, Irish LA. Daily Associations Between Sleep and Physical Activity. Int J Behav Med. 2019;26(5):5628. 


\section{PREPRINT}

52. Cox NS, Pepin V, Holland AE. Greater sleep fragmentation is associated with less physical activity in adults with cystic fibrosis. J Cardiopulm Rehabil Prev. 2019;39(1):E114.

53. Albu S, Umemura G, Forner-Cordero A. Actigraphy-based evaluation of sleep quality and physical activity in individuals with spinal cord injury. Spinal Cord Ser Cases. 2019;5(1):19.

54. Best JR, Falck RS, Landry GJ, Liu-Ambrose T. Analysis of dynamic, bidirectional associations in older adult physical activity and sleep quality. J Sleep Res. 9 sept 2018;e12769.

55. Booth JN, Bromley LE, Darukhanavala AP, Whitmore HR, Imperial JG, Penev PD. Reduced physical activity in adults at risk for type 2 diabetes who curtail their sleep. Obes Silver Spring Md. févr 2012;20(2):27884.

56. Tang NKY, Sanborn AN. Better Quality Sleep Promotes Daytime Physical Activity in Patients with Chronic Pain? A Multilevel Analysis of the Within-Person Relationship. PLOS ONE. 25 mars 2014;9(3):e92158.

57. Fanning J, Mackenzie M, Roberts S, Crato I, Ehlers D, McAuley E. Physical Activity, Mind Wandering, Affect, and Sleep: An Ecological Momentary Assessment. JMIR MHealth UHealth. 31 août 2016;4(3):e104.

58. Knufinke M, Nieuwenhuys A, Geurts SAE, Møst EIS, Maase K, Moen MH, et al. Train hard, sleep well? Perceived training load, sleep quantity and sleep stage distribution in elite level athletes. J Sci Med Sport. avr 2018;21(4):42732.

59. Mead MP, Engwall A, Irish LA. 24-HOUR HEALTH BEHAVIOR: DAILY INTERACTION OF SLEEP AND WAKING HEALTH BEHAVIORS. Dans: ANNALS OF BEHAVIORAL MEDICINE. OXFORD UNIV PRESS INC JOURNALS DEPT, 2001 EVANS RD, CARY, NC 27513 USA; 2018. p. S359S359.

60. Mead MP, Engwall AC, Irish LA. EXERCISE IS NOT ASSOCIATED WITH SUBSEQUENT NIGHT SLEEP DURATION OR CONTINUITY. Dans: ANNALS OF BEHAVIORAL MEDICINE. OXFORD UNIV PRESS INC JOURNALS DEPT, 2001 EVANS RD, CARY, NC 27513 USA; 2019. p. S823S823.

61. Youngstedt SD, Perlis ML, O'Brien PM, Palmer CR, Smith MT, Orff HJ, et al. No association of sleep with total daily physical activity in normal sleepers. Physiol Behav. 2003;78(3):395401.

62. Andrews NE, Strong J, Meredith PJ, D’Arrigo RG. Association Between Physical Activity and Sleep in Adults With Chronic Pain: A Momentary, Within-Person Perspective. Phys Ther. avr 2014;94(4):499510.

63. Skender S, Ose J, Chang-Claude J, Paskow M, Brühmann B, Siegel EM, et al. Accelerometry and physical activity questionnaires-a systematic review. BMC Public Health. 2016;16(1):515. 


\section{PREPRINT}

64. Perlis ML, McCall WV, Krystal AD, Walsh JK. Long-term, non-nightly administration of zolpidem in the treatment of patients with primary insomnia. J Clin Psychiatry. août 2004;65(8):112837.

65. Roth T, Seiden D, Sainati S, Wang-Weigand S, Zhang J, Zee P. Effects of ramelteon on patientreported sleep latency in older adults with chronic insomnia. Sleep Med. juin 2006;7(4):3128.

66. Adams SA, Matthews CE, Ebbeling CB, Moore CG, Cunningham JE, Fulton J, et al. The Effect of Social Desirability and Social Approval on Self-Reports of Physical Activity. Am J Epidemiol. 15 févr 2005;161(4):38998.

67. Singer JD, Willett JB, Willett JB. Applied longitudinal data analysis: Modeling change and event occurrence. Oxford university press; 2003.

68. Evenson KR, Wen F, Metzger JS, Herring AH. Physical activity and sedentary behavior patterns using accelerometry from a national sample of United States adults. Int J Behav Nutr Phys Act. 2015;12(1):20.

69. Tutek J, Molzof HE, Lichstein KL. Multilevel modeling of chronotype and weekdays versus weekends to predict nonrestorative sleep. Chronobiol Int. 2017;34(10):140112.

70. Tucker P, Gilliland J. The effect of season and weather on physical activity: a systematic review. Public Health. 2007;121(12):90922.

71. Shawa N, Rae DE, Roden LC. Impact of seasons on an individual's chronotype: current perspectives. Nat Sci Sleep. 2018;10:34554.

72. St-Amour S, Hains-Monfette G, Dancause KN, Cailhol L, Bernard P. Antidepressant medication use and objectively measured physical activity and sedentary behaviors in adults: a cross-sectional analysis of a nationally representative sample of Canadian adults. 2020;

73. Monk TH. Enhancing circadian zeitgebers. Sleep. 2010;33(4):4212.

*74. Chevance G, Perski O, Hekler E. Innovative methods for predicting and changing complex health behaviors: Four propositions. 2020; Translational Behavioral Medicine

75. Burg MM, Schwartz JE, Kronish IM, Diaz KM, Alcantara C, Duer-Hefele J, et al. Does stress result in you exercising less? Or does exercising result in you being less stressed? Or is it both? Testing the bi-directional stress-exercise association at the group and person (N of 1) level. Ann Behav Med. 2017;51(6):799809.

76. Rosmalen JG, Wenting AM, Roest AM, de Jonge P, Bos EH. Revealing causal heterogeneity using time series analysis of ambulatory assessments: application to the association between depression and physical activity after myocardial infarction. Psychosom Med. 2012;74(4):37786. 


\section{PREPRINT}

*77. Lorenz N, Sander C, Ivanova G, Hegerl U. Temporal Associations of Daily Changes in Sleep and Depression Core Symptoms in Patients Suffering From Major Depressive Disorder: Idiographic Time-Series Analysis. JMIR Ment Health. 2020;7(4):e17071.

*78. Bei B, Wiley JF, Trinder J, Manber R. Beyond the mean: a systematic review on the correlates of daily intraindividual variability of sleep/wake patterns. Sleep Med Rev. 2016;28:10824.

79. Gerber M, Brand S, Holsboer-Trachsler E, Pühse U. Fitness and exercise as correlates of sleep complaints: is it all in our minds? Med Sci Sports Exerc. 2010;42(5):893901.

80. Elavsky S, Gonzales JU, Proctor DN, Williams N, Henderson VW. Effects of physical activity on vasomotor symptoms: examination using objective and subjective measures. Menopause N Y NY. 2012;19(10):1095.

81. Savard M-H, Savard J, Trudel-Fitzgerald C, Ivers H, Quesnel C. Changes in self-reported hot flashes and their association with concurrent changes in insomnia symptoms among women with breast cancer. Menopause. 2011;18(9):98593.

82. Steptoe A, Freedland K, Jennings JR, Llabre MM, Manuck SB, Susman EJ. Handbook of behavioral medicine. Springer; 2010.

83. Stadnitski T, Wild B. How to Deal With Temporal Relationships Between Biopsychosocial Variables: A Practical Guide to Time Series Analysis. Psychosom Med. 2019;81(3):289304.

84. Verhagen SJ, Hasmi L, Drukker M, van Os J, Delespaul PA. Use of the experience sampling method in the context of clinical trials. Evid Based Ment Health. 2016;19(3):869.

85. Bentley KH, Kleiman EM, Elliott G, Huffman JC, Nock MK. Real-time monitoring technology in single-case experimental design research: opportunities and challenges. Behav Res Ther. 2019;117:8796.

86. Chevance, G., O. Perski, and E.B. Hekler, Innovative methods for observing and changing complex health behaviors: four propositions. Translational Behavioral Medicine, 2020.

87. Bernard P., Savard J., Steindorf K., Sweegers M.G., Courneya K.S., Newton R.U., et al. Effects and moderators of exercise on sleep in adults with cancer: Individual patient data and aggregated meta-analyses. J Psychosom Res. 2019;124

88. Zheng B, Yu C, Lin L, Du H, Lv J, Guo Y, et al. Associations of domain-specific physical activities with insomnia symptoms among 0.5 million Chinese adults. J Sleep Res. 2017;26(3):3307.

89. Vancampfort D, Stubbs B, Smith L, Hallgren M, Firth J, Herring MP, et al. Physical activity and sleep problems in 38 low-and middle-income countries. Sleep Med. 2018;48:1407. 
